Optimality Conditions in Vector Optimization
Editor:

Manuel Arana Jiménez

Spain

CO-Editor:

Gabriel Ruiz Garzón

Spain

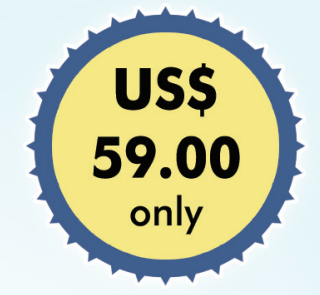

Antonio Rufián Lizana

Spain

elSBN: 978-1-60805-110-6

\title{
Optimality Conditions in Vector Optimization
}

\section{wwh.henthamseience.com/chooks/9781608051106}

\section{About the ebook}

Vector optimization is continuously needed in several science fields, particularly in economy, business, engineering, physics and mathematics. The evolution of these fields depends, in part, on the improvements in vector optimization in mathematical programming. This Ebook presents the latest developments in multiobjective optimization.

\section{Contents}

Pseudoinvexity: A good condition for efficiency and weak efficiency in multiobjective mathematical programming. Characterization

Optimality and constraint qualifications in vector optimization

- Second order optimality conditions in vector optimization problems.

- Invex functions and existence of weakly efficient solutions for nonsmooth vector optimization

- Proper efficiency and duality for differentiable multiobjective programming problems with B-( $p, r)$-invex functions

- On nonsmooth constrained optimization involving generalized type-I conditions.

For Sales Advertising Inquiries: Contact: marketing@benthamscience.org 